Article

\title{
Comparison of $X$-ray Fluorescence (XRF) and Atomic Absorption Spectrometry (AAS) Results for an Environmental Assessment at a Mercury Site in Kyrgyzstan
}

\author{
Sandra Spearman ${ }^{1, *}+\dagger^{\mathbb{D}}$, Casey Bartrem ${ }^{1,+}$, Ainash A. Sharshenova ${ }^{2,3}$, Kasiet S. Salymbekova ${ }^{3,4}$, \\ Makhmud B. Isirailov ${ }^{5}$, Saparbai A. Gaynazarov ${ }^{5,6}$, Roman Gilmanov ${ }^{7}$, Ian H. von Lindern ${ }^{1,+}$, \\ Margrit von Braun ${ }^{1,8}$ and Gregory Möller ${ }^{8}$
}

check for updates

Citation: Spearman, S.; Bartrem, C. Sharshenova, A.A.; Salymbekova, K.S.; Isirailov, M.B.; Gaynazarov, S.A.; Gilmanov, R.; von Lindern, I.H.; von Braun, M.; Möller, G. Comparison of $X$-ray Fluorescence (XRF) and Atomic Absorption Spectrometry (AAS) Results for an Environmental Assessment at a Mercury Site in Kyrgyzstan. Appl. Sci. 2022, 12, 1943. https://doi.org/10.3390/ app12041943

Academic Editor: Angeles Sanroman Braga and Emilio Rosales Villanueva

Received: 19 January 2022

Accepted: 8 February 2022

Published: 12 February 2022

Publisher's Note: MDPI stays neutral with regard to jurisdictional claims in published maps and institutional affiliations.

Copyright: (C) 2022 by the authors Licensee MDPI, Basel, Switzerland. This article is an open access article distributed under the terms and conditions of the Creative Commons Attribution (CC BY) license (https:// creativecommons.org/licenses/by/ $4.0 /)$.
1 TerraGraphics International Foundation, Moscow, ID 83843, USA; casey@terrafound.org (C.B.); ian@terrafound.org (I.H.v.L.); vonbraun@uidaho.edu (M.v.B.)

2 International Higher School of Medicine, Academic Consortium, International University of Kyrgyzstan, Bishkek 720054, Kyrgyzstan; spcpm_mhkr@mail.ru

3 Scientific and Production Centre "Preventive Medicine" of the Ministry of Health of the Kyrgyz Republic, Bishkek 720005, Kyrgyzstan; salymbekova.kasiet@mail.ru

4 Department Environmental Medicine and Human Ecology, Bishkek 720005, Kyrgyzstan

5 Interdistrict Kadamjai Center for Disease Prevention and State Sanitary and Epidemiological Surveillance of the Ministry of Health of the Kyrgyz Republic (Formerly Kadamjai SHL), Kadamjai 720221, Kyrgyzstan; israilov.60@mail.ru (M.B.I.); info@terrafound.org (S.A.G.)

6 Sanitary and Epidemiological Department for the Aydarken Region, Aydarken 720221, Kyrgyzstan

7 Médecins Sans Frontières, Kadamjai 720221, Kyrgyzstan; roman.gilmanov@gmail.com

8 Department of Soil and Water Systems, University of Idaho, Moscow, ID 83843, USA; gmoller@uidaho.edu

* Correspondence: sandra@terrafound.org

+ These authors contributed equally to this work.

Abstract: Khaidarkan, Batken Province, Kyrgyzstan is home to one of the world's largest and last primary mercury mines. Doctors without Borders (MSF) and the Ministry of Health (MOH) of Kyrgyzstan have found that the Batken region has an elevated rate of non-communicable diseases (NCD) within the country. NCD can be caused by environmental pollution. A human health risk assessment was conducted to investigate heavy metal exposure. Using a hand-held X-ray fluorescence (XRF) spectrometer for soil screening is faster and less expensive than reliance on benchscale methods. To establish a site-specific mercury conversion factor between XRF and the local $\mathrm{MOH}$ lab's Atomic Absorption Spectrometry (AAS) with a Pyrolyzer attachment, soil samples were collected in Khaidarkan and surrounding villages. Samples were analyzed by XRF in three stages: in situ, ex situ-bulk, and ex situ-sieved. The ex situ-sieved samples were analyzed by AAS. Analysis results indicate that in situ readings can be used as a qualitative tool for screening, and a conversion factor of 1.7 was most appropriate for converting ex situ-bulk/ex situ-sieved and AAS results. This analysis enables the $\mathrm{MOH}$ laboratory and others to use XRF as a quick and cost-effective monitoring tool for $\mathrm{Hg}$ contamination in soil.

Keywords: mercury; XRF technologies; environmental health; risk assessment; Atomic Absorption Spectrometry; soil analysis; applied science; mining

\section{Introduction}

One of the world's largest and last mercury mines is located in Khaidarkan, Batken Province, Kyrgyzstan. Médecins sans Frontières (MSF, Doctors without Borders) and the Kyrgyz Ministry of Health $(\mathrm{MOH})$ have found that the Batken Province has elevated levels of non-communicable diseases (NCD), confirming the findings of local physicians [1]. $\mathrm{MOH}, \mathrm{MSF}$, and TerraGraphics International Foundation (TIFO) partnered to assess environmental factors that may contribute to elevated NCD rates, using the Human Health 
Risk Assessment (HHRA). As part of the project, a goal is to provide the Kadamjay Rayon laboratory the ability to efficiently and cost-effectively screen areas for potentially harmful mercury concentrations. This research aims to develop a methodology using an X-ray fluorescence spectrometer (XRF) to characterize heavy metal exposure risks and meet this goal.

Mercury is ubiquitously used in artisanal and small-scale gold mining (ASGM) [2]. Mercury is added to ore where it forms a stable amalgam with gold, allowing miners to isolate gold from other minerals [2]. An estimated $37 \%$ of global mercury emissions are due to ASGM, accounting for 410 to 1400 tons of mercury released into the atmosphere [2]. ASGM has increased dramatically in recent years with the steep rise in gold prices, which reached 1800 USD per ounce as of January 2022 [2,3]. ASGM is an important source of income, in impoverished areas where other income sources are not available [2]. Simultaneously, these communities face multiple social and health challenges, including higher rates of NCD [2]. This research also aims to develop a rapid, cost-effective, and easily implemented methodology to identify harmful $\mathrm{Hg}$ concentrations in communities with limited resources.

$\mathrm{XRF}$ technology has been proven to be an accurate mechanism for determining concentrations of various heavy metals [4]. According to the United States Environmental Protection Agency (USEPA), a portable XRF can successfully measure $\mathrm{Hg}$, with detection limits typically ranging from 10-20 milligram per $\mathrm{kg}$ [4]. Other studies have found $\mathrm{Hg}$ detection limits of $7.4 \mathrm{mg} / \mathrm{kg}$ or less than $5 \mathrm{mg} / \mathrm{kg}[5,6]$. Some studies have found that XRF has a poor correlation with Inductively Coupled Plasma Atomic Emission Spectroscopy (ICP-AES) for measuring Hg [7]. When compared to Cold Vapor Atomic Absorption (CVAA), studies have found variable correlations for XRF analysis of $\mathrm{Hg}[4,5,8]$. However, the unreliable correlation is believed to be caused by soil samples' heterogeneity and mercury beads within the samples in that particular study [5]. Good correlations between XRF and CVAA methods have been found while accurately measuring $93 \%$ of soil samples in one study [5]. No studies were found in the scientific literature comparing XRF to Atomic Absorption Spectrometry (AAS) for $\mathrm{Hg}$ in soil. Studies comparing XRF and AAS for $\mathrm{Hg}$ in other medias found good correlations between the two methods [9,10]. Additionally, correlations have been found for other heavy metals in soil [10-13].

This study develops a relationship between XRF and an AAS with a Pyrolyzer attachment for $\mathrm{Hg}$. A Hg site-specific conversion factor was successfully found for ex situ-bulk and ex situ-sieved soil samples. Although a conversion factor could not be established for in situ soil samples, it was determined that XRF could still be used for qualitative measurements of in situ soil. The Kadamjay Sanitary and Hygienic Laboratory (SHL) will use XRF as a screening tool to identify potentially harmful mercury concentrations in soil. With the ability to screen areas quickly and inexpensively for mercury contamination, SHL will be able to prevent or reduce mercury exposures and associated adverse health effects.

\section{Materials and Methods}

\subsection{Sampling}

Soil sampling and site selection were designed to meet the project objectives of identifying high risk locations and exposure potential; some modifications were made on-site based on site conditions. Soil sampling procedures combined both United States Environmental Protection Agency (USEPA) and Kyrgyz protocols. At each site, a map was drawn identifying singular use areas, structures, and important landmarks. A Niton ${ }^{\mathrm{TM}}$ XL3t hand-held X-ray fluorescence GOLDD+ analyzer was used to screen each area in situ and results were recorded on the map. Each XRF measurement was collected for a minimum of $80 \mathrm{~s}$ through a low-density polyethylene (LDPE) material. Subareas for physical sampling were established based on the following XRF criteria: (1) concentrations exceeding 20 $\mathrm{mg} / \mathrm{kg}$ for the primary contaminants of concern $(\mathrm{Hg}, \mathrm{As}$, or $\mathrm{Sb}),(2)$ two or more high concentrations in a singular use area, and (3) a minimum of three XRF readings within the area. A low-concentration subarea was created for every ten high-concentration sites for quality assurance and quality control (QA/QC). 
Subareas requiring ex situ sampling were divided into four quadrants and five aliquots were collected: one from each quadrant (selected by randomly throwing a plastic disc) and one from the center of the area. At each aliquot location, material was collected from the organic (litter) layer, at 0-2 cm, an at 2-10 cm. If the subarea was agricultural tilled soil, the aliquot extracted was $0-20 \mathrm{~cm}$. Aliquots were homogenized in metal bowls and spooned into WhirlPak bags. Samples were recorded in a sample log and placed in an ice chest for transport. Sample holes were refilled with the remaining soil from excavation, all sampling tools were decontaminated, and sample logs were completed prior to moving to the next site.

\subsection{Ex Situ}

After being transported from the field, all samples were transferred to a chest freezer at $-18{ }^{\circ} \mathrm{C}$. Prior to laboratory analysis, samples were analyzed by XRF in bulk through the sampling bag. XRF measurements were collected three times from different locations on the sampling bag. Each XRF measurement was collected for $80 \mathrm{~s}$. In the case that one of the three XRF results significantly differed (approximately ten or more $\mathrm{mg} / \mathrm{kg}$ ) from the other results for $\mathrm{Hg}$, As, or $\mathrm{Sb}$, additional XRF measurements were taken. Frozen samples were noted, as moisture can impact XRF results [6]. Once ex situ-bulk readings were taken, samples were transferred to the freezer $\left(-18^{\circ} \mathrm{C}\right)$ until they were transported to the local laboratory.

At the laboratory, samples were sieved to $0.15 \mathrm{~mm}$ unless there was high moisture content or if ex situ-bulk measurements of $\mathrm{Hg}$ exceeded $40 \mathrm{mg} / \mathrm{kg}$ (to avoid laboratory contamination). Un-sieved samples were analyzed in bulk. Each sample was analyzed three or more times using a Lumex Versatile Atomic Absorption Spectrometry RA-915M with Pyrolyzer PYRO-915+ attachment. Upon returning from the laboratory, the samples underwent XRF ex situ-sieved analysis, using the same methodology as with ex situ-bulk samples. Following these measurements, the samples were archived in a chest freezer $\left(-18^{\circ} \mathrm{C}\right)$.

\subsection{Statistical Analysis}

XRF and AAS data were imported into RStudio (C. XRF tests shorter than $80 \mathrm{~s}$ were excluded. R statistical software version 4.0.3 (C) was used for anomaly removal and data management and analysis [14]. Sample results below XRF's varying detection limit (LOD) were assigned a value of half of the LOD. Summary statistics of XRF results for in situ, ex situ-bulk, ex situ-sieved, and AAS results of each sample were calculated for $\mathrm{Hg}, \mathrm{Sb}$, and As. Only mercury results are included in this analysis.

Histograms of XRF and AAS data were created to determine the normality of the data. An upper triangular correlation matrix was developed comparing the $\mathrm{Hg}$, $\mathrm{As}$, and $\mathrm{Sb}$ XRF readings to each other and to AAS results to determine which combinations had the potential to be analyzed for further correlation. Based on these findings, unbalanced analyses of variances (ANOVA) were conducted to ensure that the means of the data sets were statistically different. Once ANOVAs were confirmed, linear, semi-log, and log$\log$ regressions were performed on the following pairs of data for $\mathrm{Hg}$ (unless otherwise noted) [15]:

- $\quad$ AAS vs. in situ;

- AAS vs. ex situ-bulk;

- AAS vs. ex situ-sieved;

- ex situ-bulk vs. in situ;

- $\quad$ ex situ-sieved vs. ex situ-bulk;

- As ex situ-bulk vs. As in situ;

- As ex situ-sieved vs. As ex situ-bulk;

- $\quad \mathrm{Sb}$ ex situ-bulk vs. Sb in situ;

- $\quad$ Sb ex situ-sieved vs. Sb ex situ-bulk. 
If the $p$-value of the intercept was not significant with a $90 \%$ confidence interval (CI), a linear/semi-log $/ \log -\log$ regression was conducted without a Y-intercept.

\subsection{QA/QC Analysis}

QA/QC samples were dictated by the sampling criteria outlined in Section 2.1. Samples with an XRF in situ reading above $20 \mathrm{mg} / \mathrm{kg}$ and a AAS result above $20 \mathrm{mg} / \mathrm{kg}$ were considered as an acceptable prediction by XRF. False negatives (Type II error) were samples with a mean XRF in situ reading below $20 \mathrm{mg} / \mathrm{kg}$ and a mean AAS result above $20 \mathrm{mg} / \mathrm{kg}$. False-negative percentages were found using only QA/QC samples at $0-2 \mathrm{~cm}, 2-10 \mathrm{~cm}$, and a combination of all depths (excluding litter).

To determine the percentage of false positives (Type I error), samples were identified with a mean XRF in situ reading (regardless of which XRF) above $20 \mathrm{mg} / \mathrm{kg}$ and mean AAS result: below $20 \mathrm{mg} / \mathrm{kg}$, below the United States Regional Screening Level (RSL) (23 $\mathrm{mg} / \mathrm{kg})$, or below the Kyrgyz standard $(2.1 \mathrm{mg} / \mathrm{kg})$. For this analysis, all samples were used, divided by depths $0-2 \mathrm{~cm}, 2-10 \mathrm{~cm}$, and a combination of all depths (excluding litter).

\section{Results}

\subsection{Regression Results}

Histograms for $\mathrm{Hg}$, As, and Sb XRF results (in situ, ex situ-bulk, ex situ-sieved) and for AAS results were not normally distributed, and had a long tail distribution. The correlation fraction suggested the following correlations should be inspected further for $\mathrm{Hg}$, unless otherwise noted:

- $\quad$ AAS vs. in situ;

- $\quad$ AAS vs. ex situ-bulk;

- $\quad$ AAS vs. ex situ-sieved;

- $\quad$ ex situ-bulk vs. in situ;

- $\quad$ ex situ-sieved vs. ex situ-bulk;

- As ex situ-bulk vs. As in situ;

- As ex situ-sieved vs. As ex situ-bulk;

- $\quad$ Sb ex situ-bulk vs. Sb in situ;

- $\quad$ Sb ex situ-sieved vs. Sb ex situ-bulk.

Unbalanced ANOVAs performed on the above-mentioned pairs indicated significant differences between pairs' means. This validated performing regressions (linear, semi-log, and $\log -\log$ ) on all nine pairs. Summary statistics of linear regressions comparing AAS results to the different XRF types can be found in Table 1 . Linear regressions were the best correlations ( $p$-values $<99 \%$ and coefficient of determination $\left(R^{2}\right)$ values $>0.70$ ), with conversion factors ranging from 0.8-1.9. Because ex situ-bulk and ex situ-sieved linear regressions had statistically insignificant $(>90 \% \mathrm{CI}$ ) intercepts, linear regressions through the origin are presented in Table 1.

Table 1. Summary linear regression results comparing AAS to XRF. Conversion Factor (CF) is the slope of the regression line.

\begin{tabular}{cccccccc}
\hline $\begin{array}{c}\text { XRF } \\
\text { Type }\end{array}$ & $\mathbf{N}$ & $p$-Value & $\mathbf{R}^{2}$ & Intercept & CF & $\begin{array}{c}p \text {-Value of } \\
\text { Intercept }\end{array}$ & Equation \\
\hline In Situ & 79 & $<0.0001$ & 0.17 & 12 & 0.8 & 0.0013 & $\mathrm{y}=0.8 \mathrm{x}+12$ \\
\hline Ex Situ-Bulk & 154 & $<0.0001$ & 0.88 & $0^{1}$ & 1.9 & $\mathrm{NA}$ & $\mathrm{y}=1.9 \mathrm{x}$ \\
\hline Ex Situ-Sieved & 135 & $<0.0001$ & 0.87 & $0^{1}$ & 1.6 & $\mathrm{NA}$ & $\mathrm{y}=1.6 \mathrm{x}$ \\
\hline$p$-value of intercept was insignificant. & & & & &
\end{tabular}

Linear regressions comparing XRF results of different soil fractions (in situ, ex situbulk, and ex situ-sieved) had the strongest correlations (Table 2). Ex situ-bulk was the best predictor of ex situ-sieved across all three heavy metals of concern $(\mathrm{Hg}$, $\mathrm{As}$, and $\mathrm{Sb})$, 
with $R^{2}$ values ranging from $0.89-0.96$ and $p$-values $<0.0001$. Linear regressions through the origin were preformed on As ex situ-bulk vs. As in situ, and $\mathrm{Hg}$ ex situ-sieved vs. $\mathrm{Hg}$ ex situ-bulk comparisons, as both had statistically insignificant (>90\% CI) intercepts.

Table 2. Summary regression results comparing XRF soil fractions. Conversion Factor is the slope of the regression line.

\begin{tabular}{|c|c|c|c|c|c|c|c|c|c|}
\hline Element & X-Axis & Y-Axis & $\mathbf{N}$ & $p$-Value & $\mathbf{R}^{2}$ & Intercept & $\begin{array}{l}\text { Conversion } \\
\text { Factor }\end{array}$ & $\begin{array}{l}\text { Intercept } \\
p \text {-Value }\end{array}$ & Equation \\
\hline $\mathrm{Hg}$ & In Situ & $\begin{array}{l}\text { Ex Situ- } \\
\text { Bulk }\end{array}$ & 99 & $\begin{array}{c}7.08 \times \\
10^{-5}\end{array}$ & 0.15 & 8.8 & 0.3 & $\begin{array}{c}6.10 \times \\
10^{-9}\end{array}$ & $\begin{array}{c}y=0.3 x+ \\
8.8\end{array}$ \\
\hline $\mathrm{Hg}$ & $\begin{array}{l}\text { Ex Situ- } \\
\text { Bulk }\end{array}$ & $\begin{array}{l}\text { Ex Situ- } \\
\text { Sieved }\end{array}$ & 134 & $<0.0001^{1}$ & 0.89 & 0.0 & 1.1 & NA & $y=1.1 x$ \\
\hline As & $\begin{array}{l}\text { Ex Situ- } \\
\text { Bulk }\end{array}$ & $\begin{array}{l}\text { Ex Situ- } \\
\text { Sieved }\end{array}$ & 133 & $<0.0001$ & 0.96 & -10.2 & 1.4 & 0.00154 & $\begin{array}{c}y=1.4 x- \\
10.2\end{array}$ \\
\hline As & In Situ & $\begin{array}{l}\text { Ex Situ- } \\
\text { Bulk }\end{array}$ & 100 & $<0.0001^{1}$ & 0.89 & 0.0 & 1.0 & NA & $y=1 x$ \\
\hline $\mathrm{Sb}$ & In Situ & $\begin{array}{c}\text { Ex Situ- } \\
\text { Bulk }\end{array}$ & 99 & 4.91E-12 & 0.39 & 140 & 0.2 & $\begin{array}{c}4.67 \times \\
10^{-5}\end{array}$ & $\begin{array}{c}y=0.2 x+ \\
140\end{array}$ \\
\hline $\mathrm{Sb}$ & $\begin{array}{l}\text { Ex Situ- } \\
\text { Bulk }\end{array}$ & $\begin{array}{l}\text { Ex Situ- } \\
\text { Sieved }\end{array}$ & 133 & $<0.0001$ & 0.96 & -24 & 1.4 & $\begin{array}{c}7.19 \times \\
10^{-4}\end{array}$ & $\begin{array}{c}y=1.4 x- \\
24\end{array}$ \\
\hline
\end{tabular}

${ }^{1} p$-value of intercept was insignificant.

\subsection{QA/QC Results}

Data from two Niton ${ }^{\mathrm{TM}}$ XL3t hand-held $\mathrm{x}$-ray fluorescence GOLDD+ analyzers, manufactured in 2011 and 2015, were used to determine false negative and positive rates. Because the 2011 XRF had higher detection limits for $\mathrm{Hg}$, soil samples were collected if any $\mathrm{Hg}$ was detected with that XRF. At the completion of field activities, it was determined that the average detection limits of the 2011 and 2015 XRF were $14.82 \mathrm{mg} / \mathrm{kg}$ and 7.26 $\mathrm{mg} / \mathrm{kg}$, respectively. Table 3 summarizes false-negative (Type II error) rate findings by depth. The $0-2 \mathrm{~cm}$ depth had a false negative rate of $8.33 \%$, whereas the $2-10 \mathrm{~cm}$ depth had a $0 \%$ rate. Combined depths (excluding litter) had a false-negative rate of $4.08 \%$.

Table 3. False negative rate by depth. The combo depth is all depths excluding litter.

\begin{tabular}{ccccc}
\hline Depth (cm) & Total Samples & Count & Percent (\%) & Notes \\
\hline $0-2$ & 12 & 1 & 8.33 & NA \\
\hline $2-10$ & 24 & 0 & 0 & NA \\
\hline Combo & 49 & 2 & 4.08 & Excludes litter \\
\hline
\end{tabular}

Table 4 summarizes the number of false positives (Type I error) with different criteria (in-field criterion, US RSL, and Kyrgyz standard for $\mathrm{Hg}$ in soil) for collecting a physical sample. Using the Kyrgyz standard results in the highest rate of false positives for all three depth categories. The US RSL had the lowest rate of false positives across all three depths, matching the in-field criterion percentage for $0-2 \mathrm{~cm}$. 
Table 4. Percentage of false positives for all depths compared to three criteria. The in-field criterion column is the physical soil sampling criterion (Section 2.1). The Kyrgyz and US RSL columns refer to the Kyrgyz standard and US RSL for Hg in soil, respectively.

\begin{tabular}{|c|c|c|c|c|c|}
\hline Depth & $\begin{array}{c}\text { Total } \\
\text { Samples }\end{array}$ & $\begin{array}{c}\text { In-Field } \\
\text { Criterion } \\
\text { Percent } \\
(20 \mathrm{mg} / \mathrm{kg})\end{array}$ & $\begin{array}{c}\text { US RSL } \\
\text { Percent } \\
(23 \mathrm{mg} / \mathrm{kg})\end{array}$ & $\begin{array}{c}\text { Kyrgyz } \\
\text { Standard } \\
\text { Percent } \\
(2.1 \mathrm{mg} / \mathrm{kg})\end{array}$ & Notes \\
\hline $0-2$ & 97 & 2.1 & 2.1 & 9.3 & NA \\
\hline $2-10$ & 76 & 5.3 & 1.3 & 14.5 & NA \\
\hline Combo & 212 & 2.8 & 1.4 & 10.4 & Excludes Litter \\
\hline
\end{tabular}

\section{Discussion}

\subsection{AAS vs. XRF}

AAS vs. XRF regressions were interpreted in order to determine a conversion factor between XRF and AAS for total mercury in Batken, Kyrgyzstan. Semi-log and log-log regressions were performed to see if correlations improved, but it was found that linear regressions had the strongest $\mathrm{R}^{2}$ and $p$-values (Table A1). The conversion factors can be used to establish XRF as the primary screening instrument for SHL. Based on the $p$-values of zero and the highest $R^{2}$ values ( 0.88 and 0.87 , respectively), the linear regressions of ex situbulk and ex situ-sieved had the best correlations (Table 1). The in situ linear regression had a $p$-value of zero, but a $\mathrm{R}^{2}$ value of 0.17 , which is considered a poor fit to the data (Table 1 ). The in situ $\mathrm{R}^{2}$ value did improve to 0.48 in the log-log regression (Table A1). Despite this improvement, the linear regression of AAS vs. in situ was used for the conversion factor, since the improvement was not significant enough to warrant the data manipulation in the $\log$-log regressions. No comparable research was found in the literature review to either affirm or contradict the results of this study, making this study one of the first to find a correlation between XRF and AAS for determining Hg in soil. The conversion factor was determined to be 1.7 by finding the weighted mean between ex situ-bulk and ex situ-sieved.

\subsection{False Readings}

Although the in situ regressions poorly fit, false negative and positive error rates were useful for comparing XRF in situ and AAS results. According to the USEPA Superfund soil screening guidance, a study should aim for a false negative rate of $5 \%$ or below and a false positive rate of $20 \%$ or below [16]. The $0-2 \mathrm{~cm}$ depth had the highest false-negative rate $(8.33 \%)$ (Table 3). Two samples were false negatives for all depths, both of which were along waterways fed by mining wastewater and in areas prone to flooding. These samples were taken at depths $0-20 \mathrm{~cm}$ and $0-2 \mathrm{~cm}$. It is possible that both samples contained elevated levels of $\mathrm{Hg}$ below $1 \mathrm{~cm}$ XRF in situ depth), but not on the surface, possibly due to being located in a flood-prone area contaminated by water with elevated $\mathrm{Hg}$ concentrations. False negatives can also be caused by different analytical techniques between XRF and AAS, and because XRF in situ results were not at the same locations where ex situ samples were collected for AAS analysis. XRF analyzes heavy metal concentrations for a point on the soil (up to $1 \mathrm{~cm}$ deep), and multiple analyses are used to determine an average for the whole subarea (Section 2.1). On the contrary, ex situ samples are randomly taken in a subarea without any consideration of in situ analysis locations. Thus, the soil analyzed in situ is not the same as the soil analyzed ex situ (Section 2.1).

Because the $0-2 \mathrm{~cm}$ depth false negative percentage is based on a low number of samples $(\mathrm{N}=12)$, the false negative rate of all depths $(\mathrm{N}=49)$ was used. Using all depths, the false negative rate was $4.08 \%$, satisfying the USEPA Superfund recommendation.

False positive calculations were computed for three different criteria including the in-field criterion $(20 \mathrm{mg} / \mathrm{kg})$, the US RSL $(23 \mathrm{mg} / \mathrm{kg})$, and the Kyrgyz $\mathrm{Hg}$ in soil standard $(2.1 \mathrm{mg} / \mathrm{kg}$ ). Using all criteria for $\mathrm{Hg}$ in soil, all depths were less than the USEPA's Superfund false positive rate recommendation of $20 \%$. 


\subsection{XRF Soil Fractions Comparison}

Linear regressions on the three heavy metals of concern $(\mathrm{Hg}, \mathrm{As}$, and $\mathrm{Sb})$ showed strong correlations, suggesting no need for semi-log and log-log regressions. Both $\mathrm{Sb}$ and $\mathrm{Hg}$ XRF soil fraction comparisons showed that ex situ-sieved vs. ex situ-bulk had a strong correlation, whereas ex situ-bulk vs. in situ had a poor correlation. Arsenic XRF soil fraction comparisons showed that both regressions (ex situ-bulk vs. in situ, and ex situsieved vs. ex situ-bulk) have strong correlations. The ex situ-bulk vs. in situ regressions were most likely poor correlations for $\mathrm{Hg}$ and $\mathrm{Sb}$ because the soil analyzed in the XRF in situ readings was not the same soil as the ex situ samples analyzed by XRF locations (Section 4.2). The in situ results were randomly selected XRF surface readings on a sub-area, while ex situ results are random soil aliquots of that same area. Arsenic's ex situ-bulk vs. in situ regression had a strong correlation, which has been demonstrated in previous studies [17].

The ex situ-sieved vs. ex situ-bulk regressions had a strong correlation across all three heavy metals $(\mathrm{Hg}, \mathrm{As}$, and $\mathrm{Sb})$. This may be because the only difference in samples is the selection of particle size, with ex situ-sieved more likely to have higher concentrations of heavy metals [6]. Interestingly the $\mathrm{Hg}$ ex situ-sieved vs. ex situ-bulk had a conversion factor of 1.09, nearly a one-to-one ratio. This contradicts findings in other studies $[18,19]$. Unlike $\mathrm{Hg}$, ratios for $\mathrm{As}$ and $\mathrm{Sb}$ were not one-to-one. This may be because of the mining process; both $\mathrm{As}$ and $\mathrm{Sb}$ are byproducts of the process in the form of particulates, whereas $\mathrm{Hg}$ is emitted from the smelter stack as vapor molecules that can subsequently bind to fine particulates. Because $\mathrm{Hg}$ is likely bound to fine soil particulates on a molecular level, it does not increase in concentration due to sieving.

\subsection{Limitations}

$\mathrm{XRF}$ is known to underestimate concentrations when soil moisture content exceeds $40 \%$ [6]. We did not have an instrument that could provide rapid moisture content measurements. As a result, XRF readings taken on damp soil were noted ( $N=5$ for in situ, and $\mathrm{N}=9$ for ex situ-bulk). This may result in an underestimation of $\mathrm{Hg}$ in some samples. Due to moisture content, SHL was unable to sieve 17 samples and instead analyzed the bulk material. One solution to avoiding analyzing bulk material with the AAS could be to allow more time for soil samples to air dry in cool areas. Mercury has an evaporation rate of $0.33 \mu \mathrm{g} / \mathrm{m}^{2}$ per hour at $25^{\circ} \mathrm{C}$, which under the correct conditions, would allow enough time for the soil to dry without losing significant amounts of $\mathrm{Hg}$ [20]. The same drying method could be applied for ex situ-bulk XRF analyses. Future field activities could include the use of a soil moisture sensor for in situ analysis, noting areas where soil moisture is above the $40 \%$ threshold [6].

The number of QA/QC samples in the false negative analysis is low for both depths: $0-2 \mathrm{~cm}(\mathrm{~N}=12)$, and $2-10 \mathrm{~cm}(\mathrm{~N}=24)$. This low sample count possibly skewed the false negative percentages. Collecting more QA/QC samples at this depth could reduce the false negative rate.

\subsection{Use and Application}

Due to the poor fit of XRF in situ to AAS results, using XRF as a quantitative tool for predicting in situ concentrations is limited. However, XRF can be used as a qualitative screening tool for established risk criteria, and then the conversion factor of 1.7 can be applied to samples analyzed ex situ to predict AAS results. This enables estimates of mercury concentrations in sieved soil, which is more appropriate when estimating risk related to human exposures. Any soils confirmed to exceed risk criteria can then be considered for intervention and/or remediation. By using XRF to pre-screen, sampling efforts can be focused on areas with elevated levels of mercury that are of high-risk to the population. Focusing sampling efforts in this manner saves time and laboratory resources.

The cost of the Niton ${ }^{\mathrm{TM}}$ XL3t hand-held XRF GOLDD+ analyzer, which can analyze nearly an unlimited number of soil samples, is roughly equivalent to an average laboratory 
analytical cost of 220 soil samples. By using XRF and the conversion factor, SHL and MOH will have the ability to save both time and money, allowing more resources for screening programs and human health intervention to address the elevated NCD rates in the Batken region [21].

In addition, to providing SHL with an XRF mercury conversion factor, the presented methodology can be used to determine mercury site-specific conversion factors at other sites. Since conversion factors are site-specific, the methodology must be repeated for each location. Soil sampling protocols may deviate from the presented methodology to incorporate local sampling procedures.

\subsection{Future Work}

According to Kyrgyz researchers, the content of mercury in the soil in $81.6 \%$ of the samples studied exceeded the MPC $(2.1 \mathrm{mg} / \mathrm{kg})$ five-fold, and the maximum excess of mercury in the soil was 12.1-fold [22]. The highest concentrations of mercury in soil were recorded in the central, northern, and southeastern parts of the residential zone [22]. The next steps for the overall project are to jointly analyze biomonitoring and HHRA findings to inform a human health intervention program. The intervention program will be a joint effort by TIFO, MSF, MOH, and the local stakeholders. Funding is being secured to assist SHL in improving their laboratory and screening equipment.

Specific to this research, future work should include producing site-specific conversion factors from As and Sb comparing XRF to other laboratory methods. This would allow $\mathrm{SHL}$ to screen for all three heavy metals of concern $(\mathrm{Hg}$, As, and $\mathrm{Sb})$.

\section{Conclusions}

Due to the heavy exploitation of heavy metals by the USSR, Kyrgyzstan has been left with a legacy of environmental contamination. Within the Batken region, Khaidarkan is home to one of the world's largest and last primary mercury mines, which is still operating at low capacity at the time of writing. We successfully established a conversion factor for SHL of 1.7 for ex situ samples. This study is one of the first to establish a site-specific conversion factor between XRF and AAS for $\mathrm{Hg}$ in soil. Because of the continuous demand for $\mathrm{Hg}$, SHL will need to continue to monitor for harmful $\mathrm{Hg}$ concentrations. Using the established conversion factor, SHL will be able to use XRF as a quick and cost-effective screening and monitoring tool.

Author Contributions: Conceptualization, I.H.v.L.; Data curation, S.S.; Formal analysis, S.S.; Investigation, S.S., C.B., K.S.S., S.A.G. and R.G.; Methodology, C.B., M.B.I. and I.H.v.L.; Project administration, C.B., M.B.I. and S.A.G.; Resources, M.B.I.; Supervision, C.B., A.A.S. and M.B.I.; Validation, I.H.v.L. and G.M.; Visualization, G.M.; Writing—original draft, S.S.; Writing-review \& editing, S.S., C.B., A.A.S., K.S.S., R.G., I.H.v.L., M.v.B. and G.M. All authors have read and agreed to the published version of the manuscript.

Funding: The environmental health project was funded by MSF, with in-kind contributions from TIFO and MOH. Publication of this article was funded by the University of Idaho-Open Access Publishing Fund.

Institutional Review Board Statement: Not applicable.

Informed Consent Statement: Not applicable.

Data Availability Statement: The data used in this analysis are not publicly available and can only be released upon request with permission from all project partner organizations.

Acknowledgments: Firstly, we would like to thank Médecins Sans Frontières (MSF), the Ministry of Health of the Kyrgyz Republic (MOH), and TerraGraphics International Foundation for their support in the implementation of the project in the Kyrgyz Republic. Secondly, we would like to thank the following institutions and organizations (in alphabetical order): the Coordination Council and Stakeholder Committee (Batken Region, Kyrgyz Republic), Chui-Bishkek Territorial Administration, International Higher School of Medicine of the Academic Consortium of the International University 
of Kyrgyzstan, Jožef Stefan Institute, Scientific and Production Center for "Preventive Medicine", Ministry of Natural Resources, Ecology and Technical Supervision of the Kyrgyz Republic, and the University of Idaho. Lastly, we would like to thank the following individuals for their support in this research, listed in alphabetical order: Ajibek Sabirov, Bryn Thoms, Kevin Coppock, Gulzat Madmarova, Isamidin Abduraupov, Karabayev Y.A., Kasymov O.T., Milena Horvat, Sadykbekov T.A., Zholchubekova G.K.

Conflicts of Interest: The authors declare no conflict of interest.

\section{Appendix A}

Table A1. Summary statistics from the regressions on the nine pairs (Section 2.3). The regression type "through origin" refers to a regression forced through the origin. Log of an axis is referred to as $\ln ($ ). Conversion factor $(\mathrm{CF})$ is the slope of the equation. "True" equation is the equation of the line after the exponent of semi-log and log-log regression equations.

\begin{tabular}{|c|c|c|c|c|c|c|c|c|c|c|}
\hline $\begin{array}{l}\text { Regression } \\
\text { Type }\end{array}$ & $\begin{array}{l}\text { Heavy } \\
\text { Metal }\end{array}$ & $\mathrm{x}$ & Y & $\mathbf{N}$ & $p$-Value & $\mathbf{R}$ & Intercept & $\mathrm{CF}$ & $\begin{array}{l}\text { Intercept } \\
p \text {-Value }\end{array}$ & "True" Equation \\
\hline Semi-Log & $\mathrm{Hg}$ & $\ln ($ in situ) & AAS & 79 & $<0.0001$ & 0.36 & -27.70 & 22.57 & $7.74 \times 10^{-4}$ & $\mathrm{y}=\underset{22.572 \ln \mathrm{x}}{27.695}-$ \\
\hline Semi-Log & $\mathrm{Hg}$ & $\ln$ (Bulk) & AAS & 153 & $<0.0001$ & 0.69 & -46.18 & 30.89 & 0 & $\begin{array}{c}y=30.887 \ln x- \\
46.176\end{array}$ \\
\hline Semi-Log & $\mathrm{Hg}$ & $\ln ($ Sieved) & AAS & 134 & $<0.0001$ & 0.75 & -41.79 & 24.72 & 0 & $\begin{array}{c}y=24.722 \ln x- \\
41.788\end{array}$ \\
\hline Log-Log & $\mathrm{Hg}$ & $\ln ($ in situ) & $\ln (\mathrm{AAS})$ & 79 & $<0.0001$ & 0.48 & -0.76 & 1.41 & 0.048 & $y=0.4662 x^{1.4089}$ \\
\hline Log-Log & $\mathrm{Hg}$ & $\ln$ (Bulk) & $\ln (\mathrm{AAS})$ & 153 & $<0.0001$ & 0.62 & -1.06 & 1.53 & $4.29 \times 10^{-6}$ & $y=0.3476 x^{1.5283}$ \\
\hline Log-Log & $\mathrm{Hg}$ & $\ln ($ Sieved $)$ & $\ln (\mathrm{AAS})$ & 134 & $<0.0001$ & 0.75 & -41.79 & 27.72 & 0 & $y=7 \times 10^{-19} x^{27.22}$ \\
\hline Log-Linear & $\mathrm{Hg}$ & Bulk & $\ln (\mathrm{AAS})$ & 153 & $<0.0001$ & 0.36 & 1.54 & 0.06 & 0 & $\mathrm{y}=4.664 \mathrm{e}^{0.0588 \mathrm{x}}$ \\
\hline Linear & $\mathrm{Hg}$ & in situ & AAS & 79 & $<0.0001$ & 0.17 & 12.21 & 0.76 & 0.0013 & $y=0.762 x+12.2$ \\
\hline Linear & $\mathrm{Hg}$ & Bulk & AAS & 153 & $<0.0001$ & 0.76 & 0.46 & 1.65 & 0.75 & $y=1.65 x+0.46$ \\
\hline Linear & $\mathrm{Hg}$ & Sieved & AAS & 134 & $<0.0001$ & 0.78 & 0.39 & 1.53 & 0.76 & $y=1.53 x+0.39$ \\
\hline Linear & $\mathrm{Hg}$ & in situ & Bulk & 99 & $<0.0001$ & 0.15 & 8.77 & 0.30 & $6.10 \times 10^{-9}$ & $y=0.302 x+8.77$ \\
\hline Linear & $\mathrm{Hg}$ & Bulk & Sieved & 133 & $<0.0001$ & 0.79 & -0.20 & 1.10 & 0.80 & $y=1.10 x-0.20$ \\
\hline $\begin{array}{c}\text { Linear, } \\
\text { Through } \\
\text { Origin }\end{array}$ & $\mathrm{Hg}$ & Bulk & Sieved & 134 & $<0.0001$ & 0.89 & 0.00 & 1.09 & NA & $y=1.09 x$ \\
\hline $\begin{array}{c}\text { Linear, } \\
\text { Through } \\
\text { Origin }\end{array}$ & $\mathrm{Hg}$ & Bulk & AAS & 154 & $<0.0001$ & 0.88 & 0.00 & 1.89 & NA & $y=1.89 x$ \\
\hline $\begin{array}{l}\text { Linear, } \\
\text { Through } \\
\text { Origin }\end{array}$ & $\mathrm{Hg}$ & Sieved & AAS & 135 & $<0.0001$ & 0.87 & 0.00 & 1.55 & NA & $y=1.55 x$ \\
\hline Linear & As & in situ & Bulk & 99 & $<0.0001$ & 0.88 & 11.16 & 1.02 & 0.18 & $y=1.02 x+11.2$ \\
\hline Linear & As & Bulk & Sieved & 133 & $<0.0001$ & 0.96 & -10.16 & 1.36 & 0.00154 & $y=1.36 x-10.16$ \\
\hline $\begin{array}{l}\text { Linear, } \\
\text { Through } \\
\text { Origin }\end{array}$ & As & in situ & Bulk & 100 & $<0.0001$ & 0.89 & 0.00 & 1.04 & NA & $y=1.04 x$ \\
\hline Linear & $\mathrm{Sb}$ & in situ & Bulk & 99 & $<0.0001$ & 0.39 & 135.32 & 0.22 & $4.67 \times 10^{-5}$ & $y=0.223 x+135$ \\
\hline Linear & $\mathrm{Sb}$ & Bulk & Sieved & 133 & $<0.0001$ & 0.96 & -24.24 & 1.44 & 0.000719 & $y=1.44 x-24.24$ \\
\hline
\end{tabular}




\section{References}

1. Médecins Sans Frontières. Kyrgyzstan 2019 Activity Report \MSF. Available online: https://www.msf.org/international-activityreport-2019/kyrgyzstan (accessed on 1 November 2021).

2. Esdaile, L.J.; Chalker, J.M. The Mercury Problem in Artisanal and Small-Scale Gold Mining. Chem.- J. 2018, $24,6905-6916$. [CrossRef] [PubMed]

3. Gold Price Historical Data / Gold Price History. Available online: https://www.gold.org/goldhub/data/gold-prices (accessed on 1 November 2021).

4. Tetra Tech EM Inc.; Billets, S.; National Exposure Research Laboratory. XRF Technologies for Measuring Trace Elements in Soil and Sediment: Oxford X-Met 3000TX XRF Analyzer; Innovative Technology Verification Report; United States Environmental Protection Agency (EPA): Washington, DC, USA, 2006.

5. $\quad$ Brent, R.N.; Wines, H.; Luther, J.; Irving, N.; Collins, J.; Drake, B.L. Validation of handheld X-ray fluorescence for in situ measurement of mercury in soils. J. Environ. Chem. Eng. 2017, 5, 768-776. [CrossRef]

6. Horta, A.; Malone, B.; Stockmann, U.; Minasny, B.; Bishop, T.F.A.; McBratney, A.B.; Pallasser, R.; Pozza, L. Potential of integrated field spectroscopy and spatial analysis for enhanced assessment of soil contamination: A prospective review. Geoderma 2015, 241-242, 180-209. [CrossRef]

7. Wu, C.M.; Tsai, H.T.; Yang, K.H.; Wen, J.C. How Reliable is X-ray Fluorescence (XRF) Measurement for Different Metals in Soil Contamination? Environ. Forensics 2012, 13, 110-121. [CrossRef]

8. Miller, C.L.; Watson, D.B.; Lester, B.P.; Lowe, K.A.; Pierce, E.M.; Liang, L. Characterization of soils from an industrial complex contaminated with elemental mercury. Environ. Res. 2013, 125, 20-29. [CrossRef] [PubMed]

9. Janssen, J.H.; Van Den Enk, J.E.; Bult, R.; De Groot, D.C. Determination of total mercury in workroom air by atomic absorption or x-ray fluorescence spectrometry after collection on carbon-loaded paper. Anal. Chim. Acta 1976, 84, 319-326. [CrossRef]

10. Eletta, O. Determination of some trace metal levels in Asa river using AAS and XRF techniques. Int. J. Phys. Sci. 2007, 2, 56-60. [CrossRef]

11. Radu, T.; Diamond, D. Comparison of soil pollution concentrations determined using AAS and portable XRF techniques. J. Hazard. Mater. 2009, 171, 1168-1171. [PubMed]

12. Mäkinen, E.; Korhonen, M.; Viskari, E.L.; Haapamäki, S.; Järvinen, M.; Lu, L. Comparison of Xrf and Faas Methods in Analysing Cca Contaminated Soils. Water Air Soil Pollut. 2006, 171, 95-110. [CrossRef]

13. Pyle, S.M.; Nocerino, J.M.; Deming, S.N.; Palasota, J.A.; Palasota, J.M.; Miller, E.L.; Hillman, D.C.; Kuharic, C.A.; Cole, W.H.; Fitzpatrick, P.M.; et al. Comparison of AAS, ICP-AES, PSA, and XRF in Determining Lead and Cadmium in Soil. Environ. Sci. Technol. 1996, 30, 204-213. [CrossRef]

14. R Core Team. R: A Language and Environment for Statistical Computing; R Foundation for Statistical Computing: Vienna, Austria, 2021. Available online: https:/ / www.r-project.org/ (accessed on 1 November 2021).

15. Custo, G.; Boeykens, S.; Cicerone, D.; Vázquez, C. Combining XRF analysis and chemometric tools for a preliminary classification of argentine soils. X-ray Spectrom. 2002, 31, 132-135. [CrossRef]

16. United States Environmental Protection Agency. Soil Screening Guidance: User's Guide; United States Environmental Protection Agency: Washington, DC, USA, 1996.

17. United States Environmental Protection Agency. Method 6200: Field Portable X-ray Fluorescence Spectrometry for the Determination of Elemental Concentrations in Soil and Sediment; United States Environmental Protection Agency: Washington, DC, USA, 2007.

18. Fernández-Martínez, R.; Esbrí, J.M.; Higueras, P.; Rucandio, I. Comparison of mercury distribution and mobility in soils affected by anthropogenic pollution around chloralkali plants and ancient mining sites. Sci. Total Environ. 2019, 671, 1066-1076. [CrossRef]

19. Fernández-Martínez, R.; Loredo, J.; Ordóñez, A.; Rucandio, M.I. Distribution and mobility of mercury in soils from an old mining area in Mieres, Asturias (Spain). Sci. Total Environ. 2005, 346, 200-212. [CrossRef] [PubMed]

20. Lindberg, S.E.; Jackson, D.R.; Huckabee, J.W.; Janzen, S.A.; Levin, M.J.; Lund, J.R. Atmospheric Emission and Plant Uptake of Mercury from Agricultural Soils near the Almadén Mercury Mine. J. Environ. Qual. 1979, 8, 572-578. [CrossRef]

21. Sahca, P. Head of Mission, Médecins Sans Frontières (MSF); National Service Center for Environmental Publications (NSCEP): Washington, DC, USA, 2019.

22. Sharshenova, A.A.; Omurzakova, K.S.; Saipbaev, B.S.; Kozhomkulov, E.T.; Subbotin, V.V.; Adambekov, D.A.; Aitmatov, M.B. Actual Aspects of Ecological Monitoring of the Mercury-Antimony Biogeochemical Region; Ministry of Health of the Kyrgyz Republic, Scientific and Production Centre for "Preventive Medicine": Bishkek, Kyrgyzstan, 2000; p 226. 